

\section{The World Anti-Doping Code: can you have asthma and still be an elite athlete?}

The World Anti-Doping Code (the Code) has not prevented asthmatic individuals from becoming elite athletes. This review examines those sections of the Code that are relevant to respiratory physicians who manage elite and sub-elite athletes with asthma. The restrictions that the Code places or may place on the prescription of drugs to prevent and treat asthma in athletes are discussed. In addition, the means by which respiratory physicians are able to treat their elite asthmatic athlete patients with drugs that are prohibited in sport are outlined, along with some of the pitfalls in such management and how best to prevent or minimise them.

\section{-} @ERSpublications

The WADA Code places restrictions on asthma medication, but does not prevent asthma patients becoming elite athletes http://ow.ly/4mZdq0
Cite as: Fitch K. The World Anti-Doping Code: can you have asthma and still be an elite athlete? Breathe 2016; 12: 148-158.

\section{Introduction}

Despite the fact that the vast majority of asthma patients experience exercise-induced bronchoconstriction (EIB), for decades individuals with asthma, both young and old, have been recommended to exercise to improve their health and fitness [1]. For some asthma patients, the end result of such exercise prescriptions has been to achieve great success in a wide range of sports and many have become world and Olympic champions. But there are other issues or potential issues with which elite athletes with asthma may have to contend. These include training or competing in environmentally unfavourable circumstances such as having to breathe large minute volumes of cold, polluted or pollen-laden air with the potential to cause airway injury, airway hyperresponsiveness (AHR) and bronchoconstriction [2]. There is the likelihood of acute and unwanted exacerbations of asthma necessitating increased medication. In addition, asthmatic individuals who achieve elite athlete status must also be constantly aware of any restrictions on their use of asthma medications that may arise from World Anti-Doping Code (the Code) [3].

Respiratory physicians are frequently consulted by elite athletes, often on referral from their customary medical advisors, and it is essential that they have a sound knowledge of the status of the drugs that they might prescribe for elite or potentially elite athlete patients. If they do not, they may unwittingly cause their patient to return an adverse analytical finding (AAF), which could result in a doping sanction. This review aims to inform respiratory physicians of the relevant components of the Code and to indicate some of the pitfalls that can arise and how to negotiate them so as not to cause problems for their athlete patients. 


\section{The World Anti-Doping Code}

The World Anti-Doping Agency (WADA) states that its Code aims to harmonise anti-doping policies in sport and to be followed by public authorities. Most countries and almost all sports are signatories to the Code and adhere to it; the major exceptions being some North American professional sporting bodies. The Code, which is updated regularly, commenced operation in 2004 and was last updated in 2015 [3]. There are five international standards associated with the Code, two of which are important to this review.

\section{1) WADA's List of Prohibited Substances and Methods}

The first international standard is the List of Prohibited Substances and Methods (the List) which is reviewed annually on the first of January: hence the current List [4] is valid for the 2016 Summer Olympic Games. In this review, it is proposed to ignore the prohibited methods, which have no relevance for asthma medications, and replace the WADA word "substances" with drugs and medications, terms with which physicians are familiar. The List classifies prohibited drugs according to their various pharmacological categories and is divided into three sections:

- Prohibited at all times, which includes Class S3 ( $\beta_{2}$-agonists);

- Prohibited in only competition, which includes Class S9 (glucocorticoids); and

- Prohibited only in certain sports, which has no relevance to asthma.

The Code states that criteria to include a drug on the List are that it can: 1) enhance sport performance; 2) be harmful to health; or 3) be against the spirit of sport. Two of these three criteria must be fulfilled for a drug to be included. We will return to the List when discussing specific drugs used to manage asthma.

\section{2) WADA's International Standard for Therapeutic Use Exemptions}

The second international standard of relevance to respiratory physicians is International Standard for Therapeutic Use Exemptions (ISTUE) [5], the concept of which was developed by the medical commission of the International Olympic Committee (IOC) that had responsibility for the List from 1968 until WADA assumed it in the 21st century. The policy was initiated during the 1980 s when it became evident that some drugs that had recently been prohibited in sport were essential medical treatments and elite athletes like their non-athletic counterparts were prone to experience the same types of medical conditions. At that time, foremost in this dilemma were oral glucocorticoids (GCSs) as a treatment for acute asthma, autoimmune and other conditions. In 2001, this process became known as therapeutic use exemption (TUE). To be granted a TUE the athlete must demonstrate that, on the balance of probabilities, each of the following four criteria is met.

1) The drug is necessary to treat an acute or chronic medical condition and the athlete would experience a significant impairment to health if it were to be withheld.

2) The therapeutic use of the prohibited drug is highly unlikely to produce any additional enhancement of performance beyond what might be anticipated by a return to the athlete's normal state of health following the treatment.

3) There is no reasonable permitted therapeutic alternative to the use of the prohibited drug.

4) The necessity to use of the prohibited drug is not a consequence of prior use of a prohibited drug or method.

In addition to the ISTUE, WADA provides the rules and regulations that apply to TUE Committees (TUEC), the methodology of how a body should grant a TUE and the scope of its mutual recognition by other sports governing bodies and organisations [6]. It stresses the strict confidentiality of the process of TUEs. Further explanations will be provided when discussing specific drugs.

\section{How to apply for a TUE}

WADA's ISTUE web link [5] has a template form for a TUE application [5], and all national anti-doping organisations should have an application form on their website or the website of their TUEC. The completed form is submitted online.

Using the example of a prohibited inhaled $\beta_{2}$-agonist (IBA), the requirements that must be submitted for a TUEC to approve an application from an athlete are an adequate medical history and examination, including results of any investigations, spirometry or peak flow readings and an asthma diary if available. Recent evidence of AHR must be provided either with a positive bronchodilator response or a positive bronchial provocation test, which can be a physiological, either exercise or eucapnic voluntary hyperventilation, or pharmacological, e.g. mannitol, hypertonic saline, methacholine or histamine, challenge test [7]. A TUE approved for an IBA is valid for 4 years when updated data must be provided for a renewal.

A difficult aspect can be identifying which body the athlete needs to submit their application to. For international level athletes this is their international federation, e.g. the IAAF for track and field, FINA for swimming, and the UCl for cycling. For national level athletes, it is their national anti-doping organisation. Examples include the UKAD in the UK, NADA in Germany, CONI-NADO in Italy and the Swedish Sports Confederation in 
Sweden. At times, the athlete may be uncertain of his/her status. Recent changes to the Code have made it acceptable for lower level athletes to apply for a retroactive TUE when their need arises, customarily this when they achieve national level status. However, it is important to stress that the athlete's medical file should be prepared when the prohibited drug is first prescribed for retroactive submission if needed.

TUECs are composed of medical doctors, many of whom have considerable experience in managing elite athletes. Their task is to evaluate the information provided in the TUE application and ensure that it meets the necessary criteria and regulations before approving it. The author is aware that, at times, some consultants approach the task with the view that they are the expert and they do not need to justify their prescribing. This is unhelpful and likely to result in the TUEC asking for more details.

\section{The status of specific categories of drugs used to manage asthma}

Only two classes of asthma drugs are included in the List: $\beta_{2}$-agonists and GCSs. Other drugs that are permitted in sport without restriction are listed table 1.

\section{Drugs to manage asthma that are prohibited or have restraints on dosage and administration}

$\beta_{2}$-agonists that are prohibited in and out of competition

All $\beta_{2}$-agonists, including their $\mathrm{D}^{-}$and $\mathrm{L}^{-}$optical isomers, are prohibited except inhaled salbutamol, salmeterol and formoterol. All other IBAs including terbutaline, orciprenaline, reproterol and bambuterol are prohibited, while clenbuterol is sufficiently anabolic to be classed by WADA as an anabolic agent [4]. Oral $\beta_{2}$-agonists are, and have always been, prohibited.

IBA have had a variable status since being initially prohibited in sport in 1972, soon after salbutamol and terbutaline became available.
There have been periods when both salbutamol and terbutaline were permitted with notification, a 7 year period when five IBAs were permitted without notification [8], 1 year (2009) when all were prohibited, and several changes since then.

\section{Salbutamol}

Salbutamol is the short and rapidly acting IBA (SABA) that was used by more than $90 \%$ of Olympic athletes during the four Olympic Games (20022008) when it was necessary to demonstrate that an athlete had asthma or AHR to be permitted to use an IBA at the Games [8]. The List [4] states that: "the presence in urine of salbutamol in excess of $1000 \mathrm{ng} \cdot \mathrm{mL}-1$ is presumed not to be an intended therapeutic use of the substance and will be considered as an AAF".

This comment is an indirect result of a study by MARTINeAu et al. [9], published in 1992, that demonstrated that $16 \mathrm{mg}$ of long-acting oral salbutamol was distinctly anabolic. That oral salbutamol can improve exercise performance has been confirmed in subsequent publications [10]. In a 2007 review, KINDERMANN [11] noted that numerous studies had demonstrated that inhaled salbutamol does not enhance sports performance. Subsequent published research has tended to confirm this fact in doses of up to $1600 \mu \mathrm{g}$ in $24 \mathrm{~h} \mathrm{[12].}$

The contrast between the effects of the prohibited oral and the permitted inhaled salbutamol made it imperative to be able to distinguish administration by these two routes. Studies undertaken to determine this used $1600 \mu \mathrm{g}$ of inhaled salbutamol over $24 \mathrm{~h}$ with $800 \mu \mathrm{g}$ being administered in the last $4 \mathrm{~h}$ and the urinary concentration that achieved such a distinction was $1000 \mathrm{ng} \cdot \mathrm{mL}^{-1}$ [13]. This is the basis of WADA advising that the presence of a concentration of salbutamol in the urine in excess of $1000 \mathrm{ng} \cdot \mathrm{mL}^{-1}$ is presumed not to be the result of the therapeutic use of the drug, but is considered to be an adverse an AAF [4]. Although if inhaled over a $24 \mathrm{~h}$ period, the maximum allowable dose $(1600 \mu \mathrm{g})$ should, in most persons and in most instances, not result in the urinary threshold being exceeded, it may do so and has on several occasions [8]. The probable reason is the wide and unpredictable interpersonal and intrapersonal variability in the

Table 1 Asthma medications permitted in sport

\begin{tabular}{ll}
\hline Drug category & Examples \\
\hline Mast cell stabilisers (cromones) & Cromoglicate, nedocromil \\
Cysteine-leukotriene receptor antagonists & Montelukast, zafirlikast \\
Muscarinic receptor antagonists & Ipratropium, oxytropium, tiotropium \\
Xanthines & Theophylline \\
IgE selective monoclonal antibodies & Omalizumab \\
Antihistamines: $\mathbf{H}_{\mathbf{1}}$ receptor antagonists & Promethazine, loratadine, cetirizine
\end{tabular}


metabolism and excretion of salbutamol [14]. If the permitted maximal dose was to be administered rapidly, such as in 3-4 h, then it is highly likely to result in a urinary level of salbutamol above $1000 \mathrm{ng} \cdot \mathrm{mL}^{-1}$. GlaxoSmithKline demonstrated this in 1988, when 15 healthy volunteers were administered a single dose of $1200 \mu \mathrm{g}$ inhaled salbutamol and in seven out of the 15 subjects the urinary salbutamol concentrations were greater than $1000 \mathrm{ng} \cdot \mathrm{mL}^{-1}$ with one subject exceeding $3000 \mathrm{ng} \cdot \mathrm{mL}^{-1}$ [15].

Should an athlete's urine contain salbutamol in a concentration greater than $1000 \mathrm{ng} \cdot \mathrm{mL}^{-1}$, in the first instance he/she would need to provide details of his/her medical condition and medication use. On occasions, this may, and has proved to, be sufficient to exonerate the athlete. If not, WADA [4] advise that the athlete may then be required to prove through a controlled pharmacokinetic study, that the abnormal result was the consequence of the therapeutic use of a permitted inhaled dose.

This recommendation was due to one Swiss athlete whose urinary salbutamol was reported to be $\sim 8000 \mathrm{ng} \cdot \mathrm{mL}^{-1}$ after inhaling only $900 \mu \mathrm{g}$ of salbutamol in $5 \mathrm{~h}$. Subsequently, two pharmacological studies revealed his urinary salbutamol concentration was between 3000 and $4000 \mathrm{ng} \cdot \mathrm{mL}^{-1}$ after $900 \mu \mathrm{g}$ of inhaled salbutamol in 5 h [16]. Unfortunately, this athlete's abnormal salbutamol metabolism and excretion has never been replicated and the few athletes who have undergone a pharmacological study, which is an expensive exercise and difficult to organise, have rarely, if ever, had the desired outcome probably due to the capricious nature of salbutamol metabolism and excretion.

Many asthmatic individuals including some elite athletes may experience an acute exacerbation, which can be due to numerous factors including infection, allergy, pollution, inadequate preventive medication or the development of tolerance to IBAs [17], perhaps with a contribution from poor inhaler technique [18]. This can cause the athlete to inhale a larger than normal dose of salbutamol in a relatively short period. This poses no problem, unless that athlete happens to be required to have a doping test within the next $36 \mathrm{~h}$. If this did occur, the potential AAF would not result if the athlete contacted either their respiratory physician or their customary medical advisor and an application for a TUE was submitted prior to any result on their doping control test. Hence, your elite athlete patient must be made aware that if a large amount of salbutamol is inhaled relatively rapidly and shortly afterwards he/she is tested then they should ensure that an application for a TUE is submitted promptly.

It is also acceptable for an athlete with brittle asthma and a history of unpredictable exacerbations needing high doses of inhaled salbutamol in rapid succession to seek an ongoing TUE and thus be allowed to exceed the $1000 \mathrm{ng} \cdot \mathrm{mL}^{-1}$ threshold without fear of the consequences. However, in the author's experience, this is a rare occurrence in elite athletes and any such application could only succeed if the athlete was maintained on full doses of preventive medication. If granted, the TUE should be valid for 4 years. Even without this, the ISTUE does allow retroactive TUEs to be granted when emergency treatment or treatment of an acute medical condition was necessary and this could occur after the athlete's doping test result was known. Nevertheless, it is prudent to pre-empt this circumstance as advised above.

With regards to nebulised salbutamol, this route of administration is permitted, but WADA has no established a maximum daily dosage. MAZHAR et al. [19] found that lung deposition of salbutamol after $500 \mu \mathrm{g}$ of inhaled salbutamol administered via a metered dose inhaler (MDI) and spacer was equivalent to that after $5 \mathrm{mg}$ of nebulised salbutamol from a jet nebuliser. Although it is generally considered that nebulised salbutamol provides no therapeutic advantage to that delivered from an MDI and spacer except in neonates and young children [20,21], elite athletes have been prescribed regular nebulisations. In a recent case brought to the attention of the author, nebulised salbutamol caused an AAF and a subsequent pharmacological study demonstrated even higher urinary salbutamol concentrations (>4000 $\mathrm{ng} \cdot \mathrm{mL}^{-1}$ ) than had occurred during competition. Hence, it is timely to warn that regular nebulised salbutamol can trigger an AAF and if you consider that your elite athlete patient does need the drug nebulised on a regular basis, you should request a TUE in case he/she exceeds the $1000 \mathrm{ng} \cdot \mathrm{mL}^{-1}$ threshold.

\section{Salmeterol}

Two long-acting $\beta_{2}$-agonists (LABA) are permitted, salmeterol and formoterol. Salmeterol, which does not have an oral formulation, appears in urine in low concentrations and has never been demonstrated to enhance exercise performance [11], is permitted unrestrictedly if inhaled in accordance with the manufacturer's recommendations.

\section{Formoterol}

Formoterol is permitted by WADA, but as an oral preparation is available it has minor restrictions. It is permitted to a maximum dose of $54 \mu \mathrm{g}$ over $24 \mathrm{~h}$. Although not stated in the List, another WADA document "Medical Information to Support Decisions of TUECs - Asthma" [7] provides more detailed advice. This states that the maximum daily dosage is that which is delivered and not the dosage released from the inhaler. Inhalations, using both the turbuhaler and the aerolizer, deliver 
only $\sim 75 \%$ of the released dose and this should allow athlete's to administer adequate quantities of formoterol. WADA has established a urinary threshold of $40 \mathrm{ng} \cdot \mathrm{mL}^{-1}$ for formoterol and this can be exceeded, but rarely has. If an athlete is required to inhale $72 \mu \mathrm{g}$ of formoterol on a daily basis, WADA recommends that a TUE is sought.

\section{Other $\beta_{2}$-agonists}

All other IBAs are prohibited. From 1975 until 2010, terbutaline enjoyed exactly the same status in sport as its SABA counterpart, salbutamol. Terbutaline, which is marketed in an oral formulation, has similar pharmacological actions to salbutamol and is equally effective in preventing and ameliorating EIB [22]. When the decision to continue to prohibit terbutaline was made in late 2009 , there was no evidence that it enhanced performance [11]. Two recent papers by the same Danish group reported somewhat different conclusions. The first [23] reported increased muscle strength and sprint performance and the second paper disclosed no difference from placebo in a time trial [24]. However, in both studies, the dosage administered by inhalation was supramaximal at $15 \mathrm{mg}$ of inhaled terbutaline, which is several times over the maximum recommended dosage of 2-4 mg [25].

The probable reason why terbutaline remains prohibited is that no distinction between oral and inhaled administration has been demonstrated. The same research team that identified a urinary threshold to discriminate between oral and inhaled salbutamol undertook a similar study with oral and inhaled terbutaline. Although a marked difference in urinary concentrations between the two routes of administration was observed, these differences were not sufficiently significant to establish cut-off values to clearly distinguish between oral and inhaled administration [26]. Subsequent reexamination of the raw data by the author suggested that two "outliers" noted after the inhaled study may have contributed to the outcome, probably reflecting the capricious nature of the metabolism and excretion of terbutaline akin to salbutamol [14].

As the use of inhaled terbutaline by an athlete necessitates a TUE, the third criterion that must be met to approve a TUE, which states that a TUE should not be approved if there is a permitted alternative, needs to be considered. As the pharmacologically similar SABA salbutamol is permitted, this should result in the TUEC rejecting an application from an athlete to inhale the prohibited SABA terbutaline. However, appropriately WADA has acknowledged that it should have no role in prescribing medications for athletes. Hence when an athlete's recommended inhaled SABA has been terbutaline for some years, WADA accepts that it is unreasonable to demand that the athlete must suddenly switch to inhaling salbutamol and an application to continue to inhale tebutaline should be approved.

\section{Glucocorticoids are prohibited only in competition}

The List advises that the systemic use (e.g. oral or intravenous administration) of GCSs is prohibited and requires a TUE. In contrast, all inhaled GCSs are permitted in sport. Hence the Global Initiative for Asthma's gold standard for preventive treatment for asthma, EIB and AHR, inhaled GCS can be prescribed without restriction [27]. It is pleasing to note the steady improvement in the prescribing habits of doctors managing Olympic athletes with asthma/AHR, which may reflect improved knowledge of asthma management by sports and exercise physicians and team doctors and/or increased involvement of respiratory physicians (table 2).

Many elite asthmatic athletes have required a course of an oral GCS to manage an acute episode of asthma and have been granted a TUE. When systemic GCSs are used for the treatment of an exacerbation of asthma, a retroactive/emergency TUE should be submitted as soon as possible to the appropriate TUEC. However, if the athlete will not be competing for an extended period of time, no action is necessary by the prescribing doctor as the athlete's urine will not contain evidence of the GCS when he/she is next tested during a competition. However, there will be a need to apply for a TUE if the course of oral GCS is expected to continue until shortly before the athlete resumes competition. Understanding of the metabolism and excretion of GCS remains to be fully elucidated, but is considered to be rather unpredictable. All synthetic GCSs have a urinary threshold of $40 \mathrm{ng} \cdot \mathrm{mL}^{-1}$ and the presence of a GCS in an athlete's urine above this concentration can provoke an AAF [7]. It is not possible to confidently advise how long an athlete should have ceased an oral GCS before it will not be detected above $40 \mathrm{ng} \cdot \mathrm{mL}^{-1}$. From experience, one suggests a minimum of 4-5 days, but for peace of mind if there is any doubt it is prudent to apply for a retroactive TUE.

When seeking a TUE for a course of systemic GCSs for acute severe asthma, in addition to an adequate history and examination, spirometry should be submitted and would be convincing.

Table 2 Percentage of athletes taking an IBA who were also using an inhaled GCS

\section{Olympic Games}

Atlanta 1996

Athens 2004

Torino 2006

Beijing 2008

No data were available for games held in 1998, 2000 and 2002. \#: In Atlanta, IBA use was by notification only, for the other Games athletes had demonstrated asthma or AHR. 
If the athlete maintains a well-kept asthma diary, this is invaluable, more so if it includes regular peak flow or spirometry data. Occasionally, an elite athlete does require long-term low-dose GCS therapy and this will be approved provided adequate medical information to justify it is submitted.

Finally WADA advises [7] and it is stressed that:

"An athlete's health should never be jeopardized by withholding medication in an emergency."

This leads us to revert to the original question posed.

\section{The World Anti-Doping Code: can you have asthma and still be an elite athlete?}

In her autobiography, Dawn Fraser mentioned that she began to swim "to lick asthma" and her illustrious career included winning the $100 \mathrm{~m}$ freestyle in three successive Olympics (1956-1964) and holding 39 world records [28]. She experienced an acute attack of asthma shortly before the start of her first Olympics in 1956 and needed to be hospitalised, and was also troubled by asthma shortly before her $100 \mathrm{~m}$ final in Tokyo 1964. Another Australian swimmer with asthma won the $100 \mathrm{~m}$ women's butterfly in 1968. Yet these gold medals were won in a period prior to the availability of any selective IBA or any inhaled GCS.

The introduction of the Code and the List has resulted in major changes to the lives of all elite athletes. They must constantly inform authorities of their intended whereabouts and failure to do so will result in a sanction. This is because they can expect doping control officers to appear at their home, where they happen to be residing or while training at any time during the day and much of

$\%$ of athletes with asthma

$\%$ of individual medals won

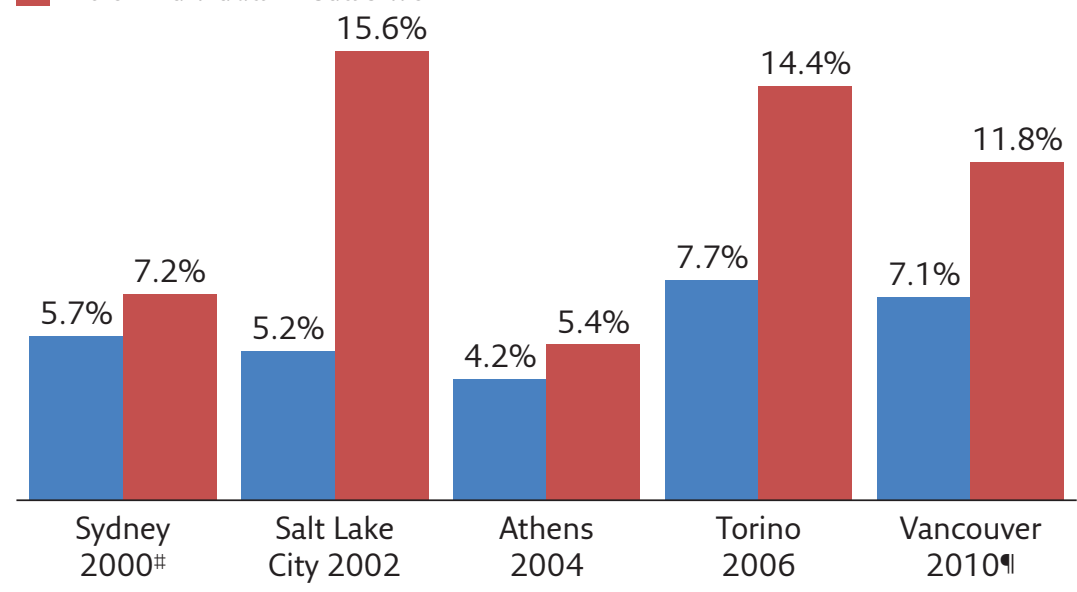

Figure 1 Percentage of athletes with asthma and corresponding percentage of individual medals won by athletes with asthma at Olympic Games 2000-2010. \#: Data based on IBA use only; ": data from WADA. the evening. Failure to comply with their request to provide a sample of urine will provoke a major sanction. All elite athletes have the responsibility to ensure that nothing that is prohibited on the List is administered by any route into their body. This can pose difficulties because many nutritional supplements, especially those made in China and purchased over the internet, may contain prohibited drugs and this may not be mentioned on the label [29].

Elite athletes with asthma must contend not only with the above, but be aware of the status of all the drugs that are prescribed to manage their asthma and know that their administration of such medications complies with the List. But athletes with asthma should be accustomed to having to meet such obligations. Some will have been provided with and adhere to an asthma action plan. They need to consult their doctor regularly for repeat prescriptions and whenever their asthma deteriorates. They may need to carry a spacer with them plus probably two inhalers, and they should be cleaning their inhalers and spacers regularly. Certainly those with brittle asthma should maintain an asthma diary and possess a peak flow meter or a small portable spirometer to assess their lung function. In addition, they should be diligently administering the appropriate medications to ensure that their airways are as patent as possible. But reflecting on the restrictions on asthma drugs that have been described and how these can be overcome with appropriate management, it should be evident to the reader that the elite athlete with asthma is not overly disadvantaged by their medical condition.

This statement can be verified when it is noted that asthma and AHR are the most common medical conditions encountered among Olympic athletes, both summer and winter, affecting between 7 and $8 \%$ of Olympic athletes [30]. Justifying the view that athletes with asthma can become elite despite the Code is the fact that at recent Games they have outperformed their non-asthmatic rivals (figure 1) [30].

The prevalence of asthma/AHR is seen principally in sports that necessitate endurance training, because almost all such Olympic sports have a much greater prevalence of asthma/AHR than in those that might be deemed sedentary sports [30]. The greater dominance of asthmatic athletes in winter Olympic Games is because the number of individual Olympic medals awarded is approximately equal between endurance and non-endurance sports. In contrast, in summer Olympic Games, 43\% of individual medals are awarded in only six sedentary sports (six (27\%) out of 22 sports) such as boxing, wrestling and shooting. Every summer and winter Olympic sport has had at least one athlete identified with asthma/AHR between 2002 and 2008 and athletes have had success in many non-Olympic 
sports including football codes [31], cricket [32] and orienteering [33].

Hence the short answer is an emphatic yes: despite the Code, you can have asthma and become a successful elite athlete.

\section{Is endurance training an occupational hazard for asthmatic athletes?}

In Torino 2006, the age of onset of asthma in athletes applying to use an IBA suggested that many winter athletes were experiencing their initial symptoms of asthma late in life and the prevalence of late onset asthma appeared to be higher than in the general population. For Beijing 2008, the IOC's questionnaire was modified so that athletes applying to use an IBA were required to provide greater clarity on this question. Analysis of the 782 athletes approved for IBA use revealed was that there was a significantly higher proportion of athletes developing asthma/AHR after the age of 25 years than those in whom it the condition commenced at the age of 25 years or younger [30].

The marked preponderance of athletes with asthma/AHR was in Olympic sports that involved endurance training such as triathlon $(25.7 \%$ of athletes at the Beijing 2008 games), cycling (17.3\% at the Beijing 2008 games), cross country skiing (16.9\% at the Torino 2006 games) and speed skating (14.9\% at the Torino 2006 games) compared with sports that did not demand many years of endurance training to achieve elite status such as weightlifting (1.2\% of athletes at the Beijing 2008 games), archery (1.6\% at the Beijing 2008 games), ski jumping (2.5\% at the Torino 2006 games) and snowboarding (3.2\% at the Torino 2006 games) strongly suggests this is a causative factor in the airway injury these athletes sustain. In addition, in their studies on retired Finnish swimmers, HeLENIUS et al. [34] reported the interesting observation that their asthma/AHR declined significantly after they retired and ceased swimming training.

For three decades, Sandra Anderson has provided evidence of the difficulty in adequately conditioning high minute volumes of air that elite endurance athletes inspire for many hours a week [35]. Any resultant airway injury will be augmented if inspired air is contaminated with pollutants such as particulate matter, chloramines or ozone, contains pollens or is very cold and dry [36]. A factor that has not been evaluated has been the size of athletes' lungs and the huge minute volumes that tall athletes can and do generate. One example is the $198 \mathrm{~cm}$ Beijing rowing gold medallist whose resting pre-test lung volumes were a forced expiratory volume in $1 \mathrm{~s}$ (FEV 1$)$ of $6.9 \mathrm{~L}$ (133\% predicted) and a forced vital capacity (FVC) of $9.6 \mathrm{~L}$ (156\% predicted). The ventilation he achieved in his positive eucapnic voluntary hyperventilation test was $1123 \mathrm{~L}$ or $187 \mathrm{~L}$ each minute and his age of onset of asthma was advised as 21-25 years. The author suspects that these huge minute ventilation volumes may contribute to a less well known high prevalence of asthma/AHR in rugby [37], where $2 \mathrm{~m}$ tall

\section{Case Study}

Athlete A's asthma was diagnosed before he was 5 years old, but was mild and managed mostly by inhaling pre-exercise terbutaline, which he also used as rescue therapy when necessary. Learning to swim at a young age, he found he enjoyed it and swimming came easily and as a teenager, Athlete A began to train almost daily and soon was selected in his national junior team. The increased training volume and countless hours swimming in chlorinated indoor pools exacerbated his asthma and inhaled budesonide and formoterol were prescribed. Over the ensuing years, Athlete A's asthma became severe and his respiratory physician had to add montelukast and at times cromoglicate. Despite being meticulous with his inhaled therapy, 2-3 times a year Athlete A's asthma would become severe enough to necessitate a course of high-dose oral prednisolone. These episodes tended to be provoked by respiratory viral infections and to occur during periods of high intensity training leading up to major competitions. At all times, his respiratory physician was meticulous in requesting a TUE for prednisolone if this was in proximity to a competition and on each occasion the TUE was granted.

At his first Olympics, he submitted an application to inhale terbutaline and formoterol which included a positive eucapnic voluntary hyperventilation test and this was approved. He won a medal at these games. He went on to compete at the Olympic Games 4 years later, despite needing courses of oral prednisolone shortly prior to both his national Olympic trials and the Games. At his second Games, his approval for terbutaline and formoterol was re-approved without need for a further challenge test, as these are valid for 4 years, and again he was a medallist. After these Olympics, Athlete A retired from swimming and his asthma improved dramatically, his medication needs declined and within 9 months, he required inhaled terbutaline only occasionally.

However, the lure of further international competition proved too great and 12 months after "retiring", Athlete A resumed training and his asthma rapidly deteriorated. His respiratory physician had to restart all his asthma medications and once again acute episodes of asthma occurred requiring oral prednisolone. He had to undergo a repeat eucapnic voluntary hyperventilation test to be approved to inhale terbutaline during his third Olympic Games and yet again, Athlete A won a medal.

\section{Lessons from this case study}

Swimmers had one of the highest prevalence of IBA use at the five Summer Olympic Games from 1996 to 2008 [30]. In addition to some being recommended to swim to assist their asthma, two "occupational" circumstances are considered to be important aetiological factors: years of both endurance training; and breathing large minute volumes of air contaminated with by-products of the chlorine used to disinfect pools [39, 40]. These factors coexisted for Athlete A. Although we need more research, the susceptibility of Athlete A to respiratory virus infections, which appeared to provoke acute asthma, may have been associated with training decreases in his immune status [41, 42]. The large number of TUEs that he had to obtain, both for IBAs and for oral prednisolone if taken shortly prior to a competition when Athlete A might be tested, were approved as all applications were submitted appropriately by his respiratory physician who was very knowledgeable as he managed many elite athletes with asthma. Athlete A's dramatic improvement in his airway stability $<12$ months after ceasing swimming does tend to support the findings on retired Finnish elite swimmers [34]. 


\section{Further reading}

Fitch KD. Therapeutic use exemptions (TUEs) at the Olympic Games 1992-2012. BrJ Sports Med 2013; $47: 815-818$. A detailed discussion on the history of TUEs and 20 years of experience of TUEs at the Olympic games.

Fitch KD, Sue-Chu M, Anderson SD, et al. Asthma and the elite athlete: summary of the International Olympic Committee's consensus conference. Lausanne, Switzerland, January 22-24, 2008. J Allergy Clin Immunol 2008; 122: 254-260. This paper and the associated online repository summarises the outcome of a Consensus Conference that examined the IOC's experience of requiring that athletes demonstrate asthma/AHR to be permitted to administer an IBA at the Olympic games. This policy was followed by WADA in 2009 and is essentially identical to the currently valid policy for all IBAs except salbutamol, salmeterol and formoterol.

Kippelen P, Anderson SD. Pathogenesis of exercise-induced bronchoconstriction. Immunol Allergy Clin North Am 2013; 33: 299-312.

Sandra Anderson has been a global giant in the elucidation of EIB and/or airway injury during the past 40 years. Her recent review of this contentious question discusses the various likely mechanisms.

athletes are common, and in other sports with many tall athletes who inspire air that is not polluted or cold. Hence, it seems a reasonable proposition to suggest that asthma/AHR may be an "occupation hazard" for many endurance trained athletes [38] and we should be devoting more attention endeavouring to prevent or reduce this outcome [36].

\section{Conclusion}

Asthma and exercise have a paradoxical relationship. Although exercise provokes bronchoconstriction in individuals with asthma, it is widely prescribed in their management. For many years, some of those who were recommended to exercise to assist their asthma have achieved outstanding sporting success. In recent years, the Code has imposed significant burdens and responsibilities on all elite athletes and even more for those with asthma. The Code places restrictions on two major classes of drugs to manage asthma, IBA and GCSs. Fortunately, inhaled salbutamol, salmeterol and formoterol are permitted in sport albeit with some limita- tions on dosage. All other IBAs are prohibited. Importantly, inhaled GCSs are permitted without restriction but their oral counterparts are prohibited. A mechanism exists to allow physicians to prescribe oral GCSs for acute exacerbations of asthma. Examination of the results of Olympic Games since the Code was introduced reveals that asthmatic athletes outperform their rivals. Finally, this paradoxical relationship between asthma and exercise could be deemed perverse when it has been demonstrated that years of endurance training can provoke airway injury, AHR and asthma in athletes with no past history of asthma. Hence, because of these consequences, it has been termed an occupational hazard to undertake the training necessary to achieve the status of an elite endurance athlete.

\section{Acknowledgements}

The author acknowledges he was a member of the IOC's Medical Commission 1985-2012, Chair of its TUE Committee 1992-2012 and Chair of its Independent Expert Asthma Panel 2001-2010.

\section{Conflict of interest}

None declared.

\section{References}

1. Scherr MS, Frankel L. Physical conditioning program for asthmatic children. J Am Med Assoc 1958; 168: 19962000.

2. Fitch KD, Anderson SD. Intensive exercise and airway hyperresponsiveness/asthma: importance of environmental factors. BrJ Sports Med 2012; 46: 379-380.

3. World Anti-Doping Agency (WADA). World anti-doping code www.wada-ama.org/en/resources/the-code/world-antidoping-code Date last accessed: March 9, 2016. Date last updated: January 1, 2015.

4. World Anti-Doping Agency (WADA). Prohibited list. www. wada-ama.org/en/resources/science-medicine/prohibited- list Date last accessed: March 10, 2016. Date last updated: January 1, 2016

5. World Anti-Doping Agency (WADA). International standard for therapeutic use exemptions (ISTUE). www.wada-ama.org/ en/resources/therapeutic-use-exemption-tue/internationalstandard-for-therapeutic-use-exemptions-istue Date last accessed: March 10, 2016. Date last updated: January 1, 2015.

6. World Anti-Doping Agency (WADA). Guidelines - therapeutic use exemptions (TUE). www.wada-ama.org/en/resources/ science-medicine/guidelines-therapeutic-use-exemptions-tue Date last accessed: March 11, 2016. Date last updated: October 2014. 


\section{Self-evaluation questions}

1. A 19-year-old female is referred to you by her family doctor. She informs you she had asthma from the age of 4 years until puberty, her treatment then was inhaled budesonide and fenoterol. Formerly a champion runner for her age group, in the past 2 years she has swum and cycled regularly and recently increased her weekly training to $12-15 \mathrm{~h}$ per week and completed two novice triathlons, winning both easily. She intends to continue and increase her training and aims to compete at a much higher level.

However, during the past month her training has been difficult because she becomes breathless easily and tires badly. Her coach thinks this is due to overtraining, but her doctor wonders if her asthma has recurred. You find her FEV 1 is only $2.1 \mathrm{~L}$ and her FVC is $3.5 \mathrm{~L}$. After inhaling $200 \mu \mathrm{g}$ of salbutamol, her lung volumes are 2.8/3.5 L. You recommence budesonide and fenoterol.

What further action if any is required?

a) Proceed to a methacholine challenge, and if positive, seek a TUE for fenoterol.

b) Switch from fenoterol to salbutamol.

c) Carefully document your findings for later use, if necessary.

d) Organise an eucapnic voluntary hyperventilation test for later use, if necessary.

2. You have overseen this 26 -year-old elite speed skater's severe asthma for 12 years and know him to be most compliant with his asthma management. For the past 5 years, his medication has been seretide accuhaler (fluticasone and salmeterol) 100/50 twice daily and inhaled salbutamol via a spacer pre-exercise and if needed. He seeks an urgent appointment and advises you that at the national championshipsm, 2 weeks ago, he won the $5000 \mathrm{~m}$ and post-race had a doping control test. He has just been informed of the results, which were that the specific gravity of the urine was 1029 and his urinary salbutamol was $1250 \mathrm{ng} \cdot \mathrm{mL}^{-1}$. As this exceeds the allowable limit of $1000 \mathrm{ng} \cdot \mathrm{mL}^{-1}$, he must demonstrate that his salbutamol intake was not excessive.

You seek further information and learn that the night prior to the championships, his chest was tight and he took two puffs of salbutamol prior to going to bed, another two puffs at 02:00 $\mathrm{h}$ when he woke coughing and wheezing, and two more on arising. He seemed better after his morning seretide, but had two puffs of salbutamol when he arrived at the track, two prior to his warm-up and another two puffs immediately pre-race. He said that he was dehydrated post-race and despite drinking copious water, could not provide a urine specimen for $90 \mathrm{~min}$.

What is your initial course of action?

a) Organise for him to have a pharmacological study at the national accredited laboratory and advise him that you will attend and oversee the test.

b) Reassure your patient that he has not broken any rules and provide him with a comprehensive letter detailing his asthma history, your knowledge of his reliability as your long-term patient and his reasonable salbutamol use in the $24 \mathrm{~h}$ pre-race.

c) Advise him that he was dehydrated and this would have caused the urinary salbutamol to be above $1000 \mathrm{ng} \cdot \mathrm{mL}^{-1}$ and you will provide him with a letter explaining that if the specific gravity of the urine was 1020 , the salbutamol concentration would be $862 \mathrm{ng} \cdot \mathrm{mL}^{-1}$ and he would have no case to answer.

7. World Anti-Doping Agency (WADA). Medical Information to Support Decisions of TUECs - Asthma. www.wada-ama.org/ en/resources/therapeutic-use-exemption-tue/medicalinformation-to-support-the-decisions-of-tuecs-asthma Date last accessed: March 12, 2016. Date last updated: August 2015.

8. Fitch KD. $\beta_{2}$-agonists at the Olympic games. Clin Rev Allergy Immunol 2006; 31: 259-268.

9. Martineau L, Horan MA, Rothwell MJ, et al. Salbutamol, a beta 2-adrenoceptor agonist increases skeletal muscle strength in young men. Clin Sci (Lond) 1992; 85: 615-621.

10. Hostrup $M$, Kalsen $A$, Auchenberg $M$, et al. Effects of acute and 2-week administration of oral salbutamol on exercise performance and muscle strength in athletes. Scand J Med Sci Sports 2016; 26: 8-16.

11. Kindermann $W$. Do inhaled beta ${ }_{2}$-agonists have an ergogenic potential in non-asthmatic competitive athletes? Sports Med 2007; 37: 95-102.

12. Koch S, Ahn JR, Koehle MS. High-dose inhaled salbutamol does not improve 10-km cycling time trial performance. Med Sci Sports Exerc 2015; 47: 2373-2379.

13. Berges R, Segura J, Ventura R, et al. Discrimination of prohibited oral use of salbutamol from authorized inhaled asthma treatment. Clin Chem 2000; 46: 1365-1375.

14. Jacobson GA, Peterson GM, McLean S. Investigation of urinary levels of salbutamol in asthmatic patients receiving inhaled therapy. J Clin Pharm Ther 1997; 22: 119-126.
15. GlaxoSmithKline (1988). GSK Study: GM198/00055/00

16. Schweizer C, Saugy M, Kamber $M$. Doping test reveals high concentrations of salbutamol in a Swiss track and field athlete. Clin J Sport Med 2004; 14: 312-315.

17. Wraight JM, Hancox RJ, Herbison GP, et al. Bronchodilator tolerance: the impact of increasing bronchoconstriction. Eur Respir J 2003; 21: 810-815.

18. Price D, Bosnic-Anticevich S, Briggs A, et al. Inhaler competence in asthma: common errors, barriers to use and recommended solutions. Respir Med 2013; 107: 37-46.

19. Mazhar SH, Ismail NE, Newton DA, et al. Relative lung deposition of salbutamol following inhalation from a spacer and a Sidestream jet nebulizer following an acute exacerbation. BrJ Clin Pharmacol 2008; 65: 334-337.

20. Dhuper S, Chandra A, Ahmed A, et al. Efficacy and cost comparisons of bronchodilator administration between metered dose inhalers with disposable spacers and nebulizers for acute asthma treatment. J Emerg Med 2011; 40: 247-255.

21. Newman KB, Milne S, Hamilton C, et al. A comparison of albuterol administered by metered-dose inhaler and spacer with albuterol by nebulizer in adults presenting to an urban emergency department with acute asthma. Chest 2002; 121: 1036-1041.

22. Vilsvik J, Schaanning J, Ståhl E, et al. Comparison between Bricanyl Turbuhaler and Ventolin metered dose inhaler in the treatment of exercise-induced asthma. Ann Allergy 1991; 67: 315-318. 
23. Hostrup M, Kalsen A, Bangsbo J, et al. High-dose inhaled terbutaline increases muscle strength and enhances maximal sprint performance in trained men. Eur J Appl Physiol 2014; 114: 2499-2508.

24. Kalsen A, Hostrup M, Karlsson S, et al. Effect of inhaled terbutaline on substrate utilization and 300-kcal time trial performance. J Appl Physiol (1985) 2014; 117: 1180-1187.

25. Sweetman SC, ed. Martindale: the Complete Drug Reference. 37th Edn. London, Pharmaceutical Press, 2011; p. 1254

26. Roig M, Bergés R, Ventura $R$, et al. Quantification of terbutaline in urine by enzyme-linked immunosorbent assay and capillary electrophoresis after oral and inhaled administrations. J Chromatogr B Analyt Technol Biomed Life Sci 2002; 768: 315-324.

27. Global Initiative for Asthma (GINA). 2015 GINA Report, Global Strategy for Asthma Management and Prevention. http://ginasthma.org/ Date last accessed: March 14, 2016. Date last updated: 2015.

28. Frazer D. Gold medal girl. Melbourne, Landsdowne, 1965.

\section{Suggested answers}

1. C.

This low level athlete does not require a TUE, but may do so in the future. You have evidence of a positive bronchodilator test, which remains valid for four years and can be submitted as evidence should the athlete's status necessitate a TUE.

2. b.

WADA do not permit specific gravity correction down to 1020 for exogenous drugs, but do for endogenous substances. Some believe that they should. Your letter should cause the national anti-doping organisation to exonerate the athlete, although it may not immediately and you may have to provide evidence in person at his tribunal hearing to achieve this result. If it does not exonerate him, or if it does and WADA appeals the decision (WADA has a habit of doing so), a pharmacological study could be organized, but as his alleged 'offense' occurred after only $1200 \mu \mathrm{g}$ of inhaled salbutamol, with $600 \mu \mathrm{g}$ within around $4 \mathrm{~h}$ of the skater providing a urine specimen, it is doubtful if the study will assist his cause.
29. Geyer H, Parr MK, Koehler K, et al. Nutritional supplements cross-contaminated and faked with doping substances. J Mass Spectrom 2008; 43: 892-902.

30. Fitch KD. An overview of asthma and airway hyperresponsiveness in Olympic athletes. Br J Sports Med 2012; 46: 413-416.

31. David Beckham admits he has life-long asthma 20 November 2009. www.dailymail.co.uk/tvshowbiz/article-1230404/ David-Beckhams-biggest-secret-revealed-star-admitsAsthma.html. Date last accessed: March 15, 2016.

32. Darren Gough - I refuse to be bowled over by asthma 1 November 2009. www.dailymail.co.uk/health/article-1224318/DARREN-GOUGH-I-refuse-bowled-asthmahaunted-teens.html. Date last accessed: March 15, 2016.

33. Norqvist J, Eriksson L, Söderström L, et al. Self-reported physician-diagnosed asthma among Swedish adolescent, adult and former elite endurance athletes. J Asthma 2015; 52: 1046-1053

34. Helenius I, Rytilä P, Sarna S, et al. Effect of continuing or finishing high-level sports on airway inflammation, bronchial hyperresponsiveness, and asthma: a 5 -year prospective follow-up study of 42 highly trained swimmers. J Allergy Clin Immunol 2002; 109: 962-968.

35. Kippelen P, Anderson SD. Airway injury during highlevel exercise. BrJ Sports Med 2012; 46: 385-390.

36. Kippelen P, Fitch KD, Anderson SD, et al. Respiratory health of elite athletes - preventing airway injury: a critical review. BrJ Sports Med 2012; 46: 471-476.

37. Falvey EC, McCarthy C, O'Connor TM, et al. Exerciseinduced bronchoconstriction and exercise testing in an international rugby union team. Thorax 2010; 65: 843-844.

38. Price OJ, Ansley L, Menzies-Gow A, et al. Airway dysfunction in elite athletes-an occupational lung disease? Allergy 2013; 68: 1343-1352.

39. Gleeson M, McDonald WA, Cripps AW, et al. The effect on immunity of long-term intensive training in elite swimmers. Clin Exp Immunol 1995; 102: 210-216.

40. Gleeson M, Pyne DB. Special feature for the Olympics: effects of exercise on the immune system: exercise effects on mucosal immunity. Immunol Cell Biol 2000; 78: 536-544.

41. Bougault V, Turmel J, Levesque B, et al. The respiratory health of swimmers. Sports Med 2009; 39: 295-312.

42. Bougault V, Boulet LP. Airways disorders and the swimming pool. Immunol Allergy Clin North Am 2013; 33: 395-408. 